\title{
Adjuvant Consensus: A Breast Cancer Patient Web Tool
}

\author{
Walter Jonat $^{a} \quad$ Christoph Mundhenke $^{a} \quad$ Manfred Kaufmann $^{b}$ \\ a Universitäts-Frauenklinik Kiel, \\ b Universitätsfrauenklinik, Johann-Wolfgang-Goethe-Universität Frankfurt/M., Germany
}

Key Words

Breast cancer · Internet · Counseling

\section{Summary}

The new web tool Adjuvant Consensus gives the user access to the most recent information on how world leading experts suggest to treat a specific breast cancer with systemic therapy. By entering tumor characteristics, age, and menopausal status, the user can find out what experts and national guidelines suggest for this specific tumor. The basis for the suggested treatment options and guidelines are coming from 2 world leading resources: They reflect the reached expert consensus on the implications of evidence for patient treatment selection at the world leading consensus conference on adjuvant therapy held regularly in St. Gallen, and the 'Clinical Practice Guidelines in Oncology' for breast cancer published in the US by the National Cancer Center Network in January 2007. The calculated treatment options include the suggested systemic treatment - chemotherapy, hormonal therapy, and antibody therapy, alone or in combination - and the duration and sequence of therapy. Furthermore, the user can find information on the mode of action and important side effects of the different drugs.

\section{Introduction}

Despite multiple efforts from the medical and scientific community and major patient advocacy groups, there still is an

\section{Schlüsselwörter \\ Brustkrebs · Internet · Beratung}

\section{Zusammenfassung}

Die neue internetbasierte Plattform Adjuvant Consensus bietet den Nutzern Zugang zu den aktuellsten Informationen über Vorschläge der weltweit führenden Brustkrebsexperten zur systemischen Behandlung einer Brustkrebserkrankung. Nach Eingabe von Tumorcharakteristika, Alter und Menopausenstatus erfährt die Nutzerin Therapievorschläge von Experten und basierend auf internationalen Leitlinien. Die Grundlagen der vorgeschlagenen Therapiemöglichkeiten stammen aus zwei weltweit angesehenen Quellen: Sie spiegeln den aktuellen Expertenkonsens wieder, der auf der regelmäßig in St. Gallen stattfindenden Consensus-Konferenz zur adjuvanten Therapie des Mammakarzinoms erzielt wurde, sowie die aktuellen Leitlinien "Clinical Practice Guidelines in Oncology" zur Therapie des Mammakarzinoms, die vom National Cancer Center Network im Januar 2007 in den USA veröffentlicht wurden. Die berechneten Behandlungsoptionen beinhalten die vorgeschlagenen systemischen Therapien - Chemotherapie, endokrine Therapie, und Antikörpertherapien - sowie Erläuterungen, ob die Medikamente jeweils allein oder in Kombination gegeben werden sollten, und für welche Dauer und in welchen Sequenzen die Therapien appliziert werden. Darüber hinaus findet die Nutzerin Informationen zum Wirkprinzip der Medikamente und zu deren Nebenwirkungen.

unmet need for patients with breast cancer to understand their disease. This is especially true within the complex area of systemic therapy. As soon as a patient has learnt her diagnosis and has undergone breast surgery, multiple questions and con-

\begin{tabular}{ll}
\hline KARGER & ( 2008 S. Karger GmbH, Freiburg \\
Fax +49 7614520714 & Accessible online at: \\
$\begin{array}{l}\text { E-mail Information@Karger.de } \\
\text { www.karger.com }\end{array}$ & www.karger.com/brc
\end{tabular}




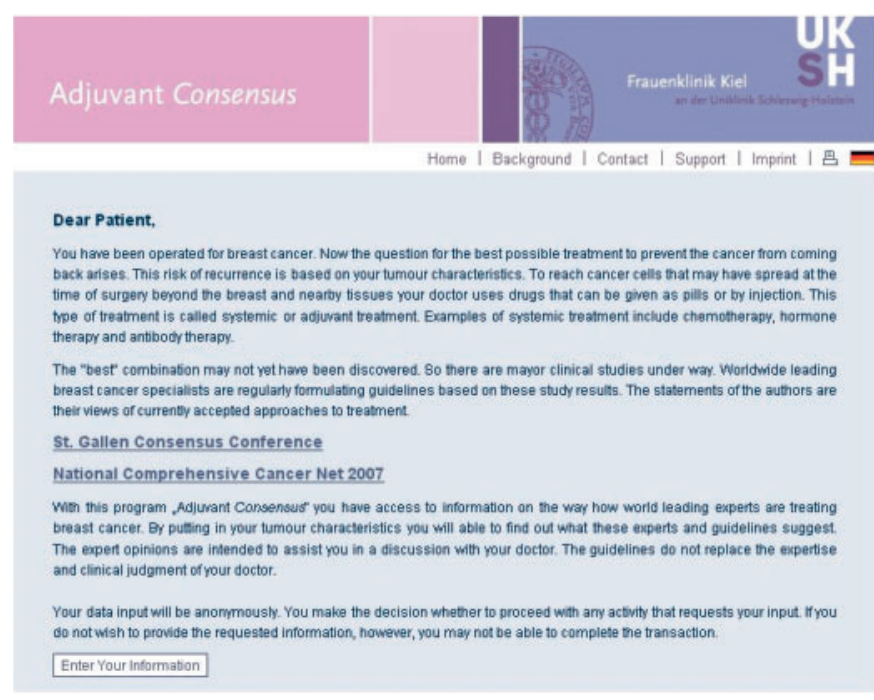

Fig. 1. Home page.

cerns regarding her future life and chances to prevent a recurrence arise. Naturally, most patients want to know their prognosis and receive the best available treatment. Most patients receive a form of adjuvant (prophylactic) systemic therapy including chemotherapy, hormonal therapy, and small molecules. In many cases, combinations of these therapies are suggested.

The prognosis can be calculated by using the web tool Adjuvant!Online. The recommended method for using Adjuvant!Online is to have an experienced health professional enter the data of a given patient on the website. Calculation results for the adjuvant regimens and the toxicity review should be printed out and be further discussed. This web tool is not recommended for use by patients in the absence of support of a health professional. There are a number of areas where experienced clinicians disagree. In these instances Adjuvant!Online may present an evidence-based interpretation and opinion, but this is not necessarily the only point of view. The new web tool Adjuvant Consensus (www.adjuvantconsens.com) gives the user access to the most recent information on how world leading experts suggest to treat a specific breast cancer with systemic therapy. By entering tumor characteristics, age, and menopausal status, the user can find out what experts and national guidelines suggest for this specific tumor. The basis for the suggested treatment options and guidelines are coming from 2 world leading resources: They reflect the reached expert consensus on the implications of evidence for patient treatment selection at the world leading consensus conference on adjuvant therapy held regularly in St. Gallen, and the 'Clinical Practice Guidelines in Oncolo$\mathrm{gy}^{\mathrm{TM}}$, for breast cancer published by the National Cancer Center Network (NCCN) in January 2007. The calculated treatment options include the suggested systemic treatment chemotherapy, hormonal therapy, or antibody therapy, alone or in combination - and the duration and sequence of thera-

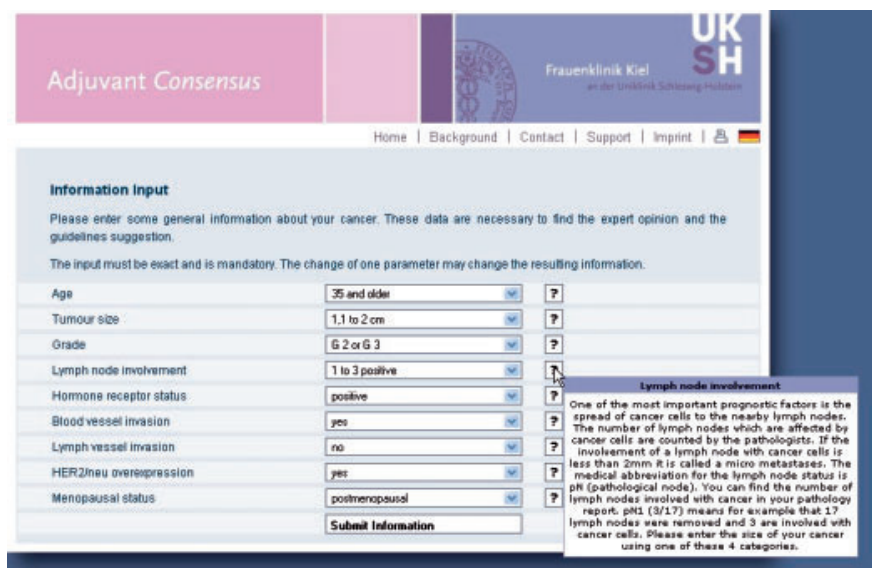

Fig. 2. 'Information Input' page.

py. Furthermore, the user can find information on the mode of action and important side effects of the different drugs. The suggested treatment options are intended to assist both the patient and the doctor in their discussion and decision making. This easy to use web tool is developed for the use by breast cancer patients and the non-medical community using the internet. It also may help doctors and the medical community to find out latest expert opinions and guidelines on adjuvant breast cancer therapy. It is multilingual (so far, German and English), and is adapted as soon as new guidelines become available (i.e., St. Gallen 2007). The user's data input is anonymous and free of charge. All web pages of the tool are printable.

\section{The Tool}

\section{Home Page}

On the home page (fig. 1), the breast cancer patient (user) can get basic information about the tool. There is a direct link to the home pages of the St. Gallen Conference and the NCCN, the resources on which the tool is based. She can go to the background window or proceed with the data input.

By ticking the 'Enter Your Information' box, the user gets to the next page.

\section{Information Input}

On the 'Information Input' page (fig. 2), the user enters her tumor characteristics, age, and menopausal status. If necessary, she may ask her doctor for this information. The data input is categorized based on the categories from St. Gallen and the NCCN. By clicking the question mark box, the user 

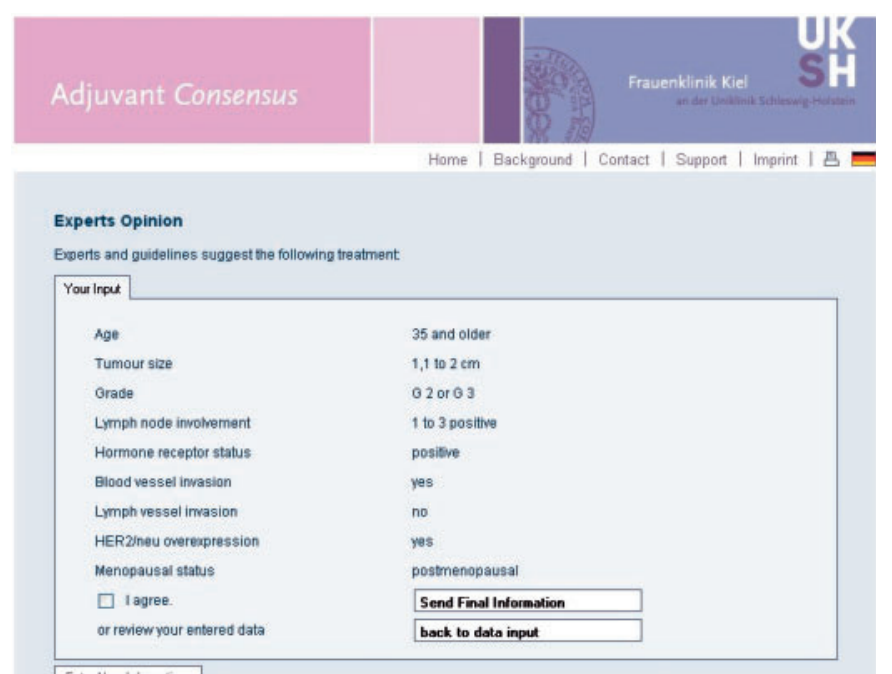

Fig. 3. 'Expert Opinion' page, displaying data entered by the user.

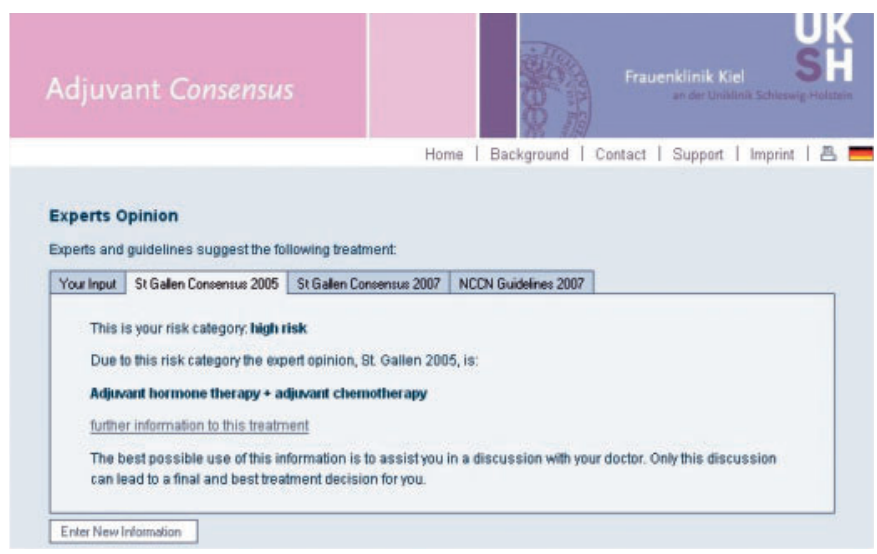

Fig. 5. Experts opinion for the tumor information entered above from St. Gallen 2005.

can get further information on each factor. Figure 2 illustrates the data of a patient and information on lymph node involvement. If she agrees by ticking the 'Submit Information' box, the data will be sent. These data are specific for the tumor but do not include any personal information. The input is anonymous.

\section{Experts Opinion}

On this page (fig. 3), the user sees the data as she has entered them. She has a chance to go back to review her entered input or change it. She can agree by ticking the 'I agree' confirmation box.

Now, the data input is calculated, and three new tabs appear (fig. 4). So far, the user can choose between 2 expert opinions and guidelines she may want to see. Figure 5 shows the ex-

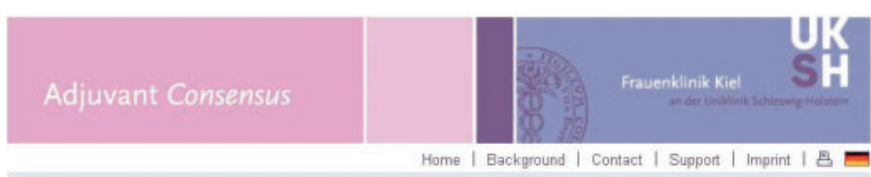

\section{Experts Opinion \\ Expents and guidelines suggest the following treatment}

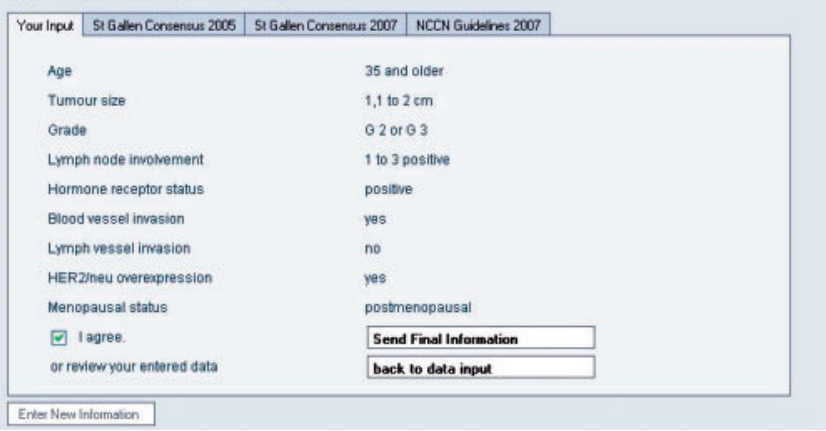

Fig. 4. 'Expert Opinion' page, displaying 3 tabs which allow the user to access expert opinions and guidelines.

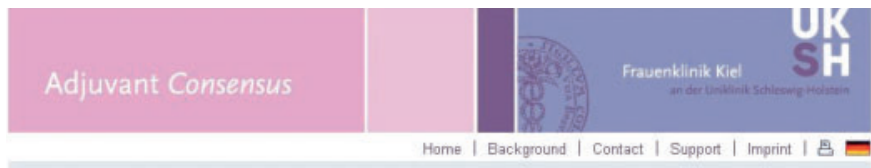

Experts Opinion

Expens and guidelines suggest the following treatment

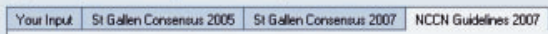

The NCCN Practice Guidelines in Oncology-r.1.2007 suggest the following treatment

Adilinant hormone therany + aditivant chemotherapy + trasturumat

Further information to mis treatment

The best possibie use of this information is to assist you in a discussion with your doctor. Onty this discussion

can lead to a final and best treatment decision for you.

Enrie New intumsten

Fig. 6. Treatment suggestion by the "Clinical Practice Guidelines in Oncology' for the tumor information entered above.

perts opinion for the tumor information entered above from St. Gallen 2005.

Another option is shown by ticking the NCCN tab (fig. 6). This informs the user which treatment the 'Clinical Practice Guidelines in Oncology' for breast cancer suggest for this specific situation.

\section{Further Information to this Treatment}

If the user is interested in further information, she may click on 'further information to this treatment' (fig. 6). The window shown in figure 7 will open (only part of it is shown, the user can scroll within the window). The information in this window explains the duration and sequence of a therapy the user may or should receive. The user can proceed as far as is summarized within the consensus statement and the guidelines on de- 


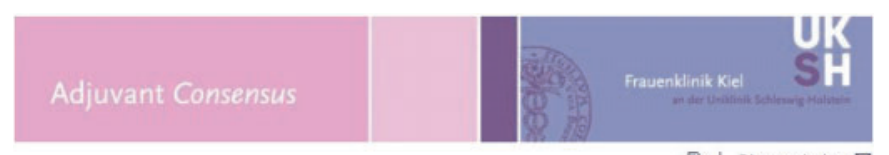

量 | Close window

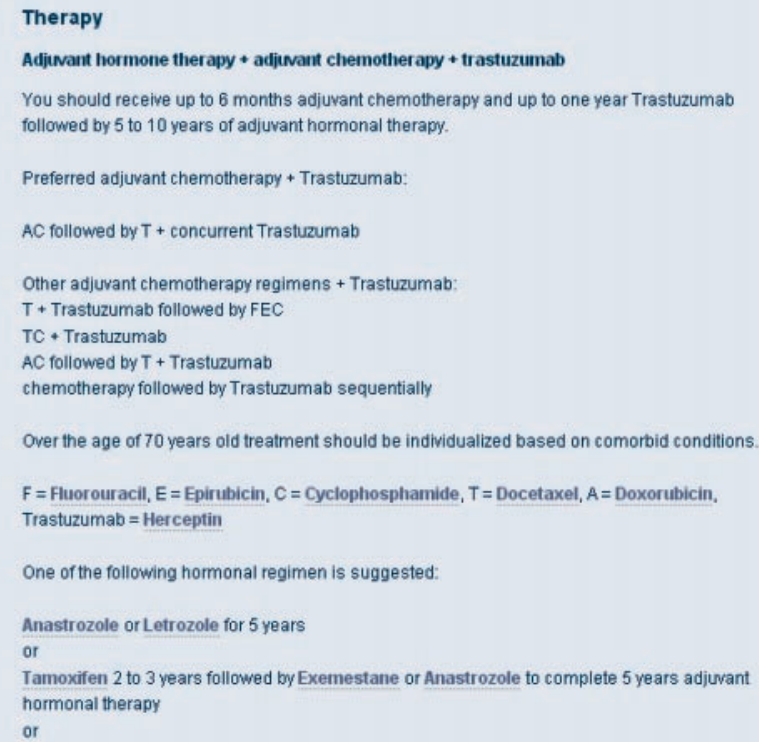

Fig. 7. Window providing the user with further information on a certain treatment.

tailed therapies. By ticking a specific drug, she will get information on the mode of administration and action and on important side effect profiles of this drug. An example is given in figure 8 for letrozole.

\section{Contact}

Going back to the home page by clicking the appropriate tab, the user has the possibility to contact me (W.J.). She may send her comments, questions, or suggestions (fig. 9).

\section{Support}

This page informs the user about the possibility to support the further development of this tool and the resources which are supporting this work.

\section{Imprint}

This page gives some information about the tool.

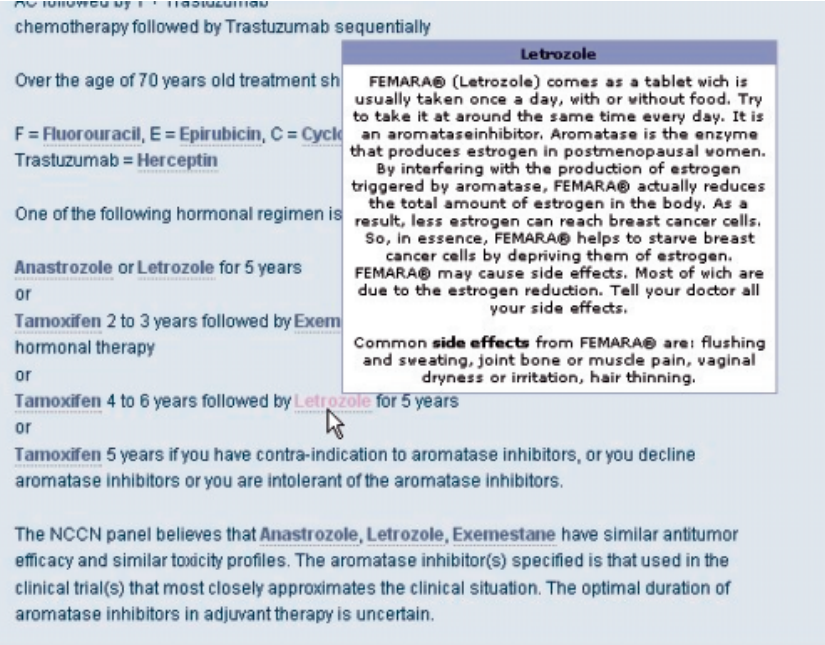

Fig. 8. Further information on letrozole treatment.

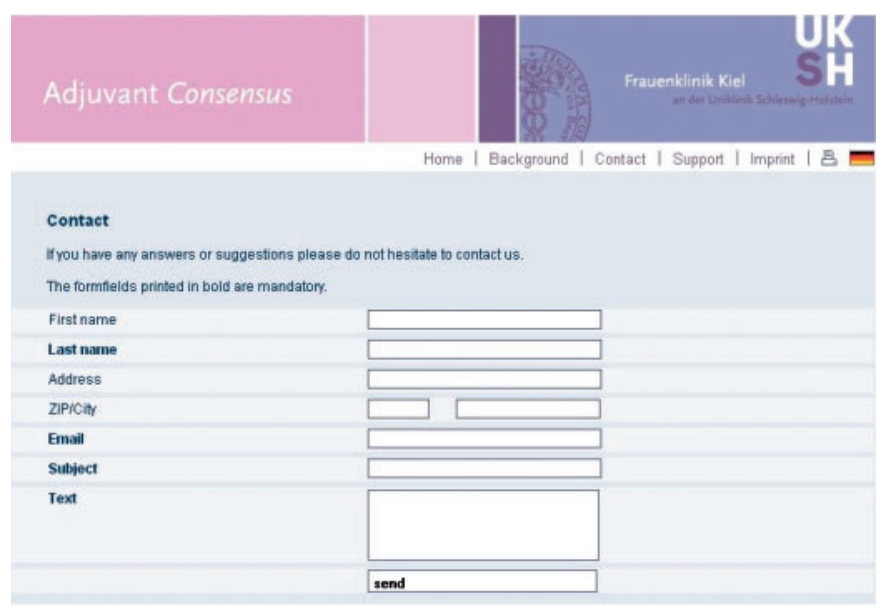

Fig. 9. Contact page.

\section{Conclusion}

Adjuvant Consensus is a web tool which gives the user access to the most recent information on how world leading experts suggest to treat a specific breast cancer with systemic therapy. It is an independent source of information. By entering tumor characteristics, age, and menopausal status, the user can find out what experts and national guidelines suggest for this specific tumor. Further languages and, if applicable, regional breast cancer treatment standards, such as established by the AGO Breast Cancer Group, will be included. These recommendations will only be seen within the specified language and residential area of the user. Furthermore, it is planned to make the tool available for medical professionals. 